\title{
Attempted suicide: Mode and its distribution characteristics among soldiers and their family
}

\author{
Rawal N', Shrestha DB², Katuwal N', Pathak $\mathrm{N}^{3}$
}

${ }^{1}$ Namrata Rawal, Consultant; ${ }^{1}$ Nagendra Katuwal, Consultant; Neuro-Psychiatrist, ${ }^{2}$ Dhan Bahadur Shrestha, Intern, Shree Birendra Hospital (SBH), Chhauni, ${ }^{3}$ Nishita Pathak, Consultant Neuro-Psychiatrist, Armed Police Force Hospital, Kathmandu.

\begin{abstract}
Background: Suicide and Parasuicide are the serious public health problem, which is higher in females, younger people and among unemployed males. Parasuicide being common include mental disorders such as mood disorder, personality disorders, and substance abuse. Para-suicides among military personnels and their families have not been studied yet in Nepal. This study is carried out to understand the demography of parasuicide and its mode.

Methodology: This is a hospital record based study including data of last five years (2011-2016 AD) where individuals with history of parasucide were assessed after they were referred to the neuropsychiatry department of military hospital. Their personal detail records and mode of parasuicide were retrieved using simple data retrieval sheet and entered and analysed after approval from local institutional review committee.

Results: Among 65 cases attempting suicide, 52.3\% were males and $47.7 \%$ were females. Median age of individuals attempting suicide was 29 years. Most of the cases $(32,49.2 \%)$ attempted suicide were family member of the soldiers then followed by serving and retired soldiers. Among the suicide attempters, organo-phosphorous (OP) poisoning was the commonest mode of suicide attempt $(25,43.1 \%)$, followed by drug overdose/ hanging each $11(16.9 \%)$ cases.

Conclusion: The study showed that among the soldiers and their family, the commonest mode of parasuicide is OPpoisoning and seen in young males.
\end{abstract}

Key words: Nepal; OP poisoning; Parasuicide

\section{INTRODUCTION}

uicide and attempted suicide are the serious public $\checkmark$ health problem of the current century and more aggravated by the unemployment ${ }^{1}$. Literature indicates parasuicide as a serious public health problem with reported annual rate of 2.6 to 1,100 per 100,000 globally, and lifetime prevalence of 720 to 5,930 per $100,000^{1}$. Parasuicide is higher in females and younger people and among unemployed males ${ }^{1-3}$. Common means of the para suicide are drug poisoning following violent methods of self-harm ${ }^{2-3}$. Among the drug poisoning as the cause for the suicide; psychoactive drugs, were common like benzodiazepines, classic neuroleptics etc $^{3}$. Also, most of the individuals with mental disorders

Address for correspondence

Dr. Namrata Rawal

Consultant; Neuro-Psychiatrist

Shree Birendra Hospital, Chhauni

E-mail:namrata_mahara@yahoo.com and mood disorders being the prominent one ${ }^{3}$. Studies also show, parasuicide being common in psychotic disorders, substance-induced psychotic disorder and in persons with comorbid substance use disorders ${ }^{4}$. Nepal is an agriculture based country so readily availability of the pesticide facilitates their use as common attempt for suicide in $\mathrm{Nepal}^{5}$.

In context of Nepal exact nation-wide data on suicide and para-suicide is lacking. Though many studies have been done in suicide and para-suicides ${ }^{5}$, no such studies have been conducted in Nepal in military personnels and their families. The study is carried out to understand the demography of parasuicide and its mode in military personnels and their families who are the vulnerable groups. Suicidal attempts are often encountered military and their families and is an important markers to understand the mental health problems of this population. 


\section{METHODOLOGY}

This is a cross-sectional study based on hospital record with data of last five years from 2068 BS to 2073 BS (20112016) where individual with the history of parasuicide visiting or referred to the neuropsychiatry department of military hospital were assessed. Total of 65 cases of parasucide were referred from various department (Emergency, medicine and others) to department of psychiatry for evaluation and further management. Their personal details and mode of parasuicide were retrieved from department records, using non-validated data retrieval sheets, and analysis was done using SPSS version 22.

This study on recorded data was done after approval from institutional review committee of Nepalese army institute of health sciences from August- November 2017 over period of three months.

\section{RESULTS}

Among 65 cases of attempted suicide, 34(52.3\%) were males and 31 (47.7\%) were females. Median age of the individuals attempting suicide was 29 years. Modal value for age was 24 with maximum of 73 years and minimum of 16 years. Most of the individuals $(32,49.2 \%)$ who attempted suicide were family members of the soldiers followed by serving and retired soldiers. Since the bulk of the beneficiaries in the army are the family of the soldiers which could be the reason for high representation in this findings. Then follows the serving soldiers, it may be due to difficulty maintaining standard of high demand posed by the service, separation from family in remote postings and frustration in the job (Table 1.)

The table below (Table 2.) shows demographic profile of attempted suicide cases. Most of them $(42,64.6 \%)$, were married.

Among the cases of attempted suicides, OP poisoning was the commonest mode of suicide $(25,43.1 \%)$, followed by drug overdose/ hanging each 11 (16.9\%) and other modes were other substance or unknown poisoning, jumping from height (Table 3.). Other poisoning included rat poison (Rodenticides) and phenolic compounds while drug overdose included benzodiazepines and over the counter drugs like Paracetamol etc.

Among total cases, 9 (13.84\%) cases reported to have neuropsychiatric co morbidities like five were under treatment for depression, two were for psychosis, one each for alcohol dependent syndrome and epilepsy.
Table 1: Status of the client

\begin{tabular}{lcc|}
\hline Status & Number (N) & Percent (\%) \\
\hline Serving & 29 & 44.6 \\
\hline Retired & 4 & 6.2 \\
\hline Family & 32 & 49.2 \\
Total & $\mathbf{6 5}$ & $\mathbf{1 0 0}$ \\
\hline
\end{tabular}

Table 2: Demographic Variables

\begin{tabular}{llcc}
\hline Demographic variables & Frequency & Percent \\
\multirow{3}{*}{ Gender } & Male & 34 & 52.3 \\
& Female & 31 & 47.7 \\
\multirow{3}{*}{ Education } & Below SLC & 40 & 61.5 \\
& Above SLC & 25 & 38.5 \\
\multirow{2}{*}{ Marital Status } & Unmarried & 23 & 35.4 \\
\cline { 2 - 3 } & Married & 42 & 64.6 \\
& Service & 34 & 52.3 \\
& Housewife & 18 & 27.7 \\
& Student & 8 & 12.3 \\
& Farmer & 3 & 4.6 \\
& Business & 2 & 3.1 \\
\hline
\end{tabular}

Table 3: Mode of suicidal attempt

\begin{tabular}{lcc|}
\hline Mode of suicide & Frequency & Percent \\
\hline OP Poisoning & 28 & 43.1 \\
\hline Drug overdose & 11 & 16.9 \\
\hline Other Poisoning & 5 & 7.7 \\
\hline Jump from height & 3 & 4.6 \\
\hline Hanging & 11 & 16.9 \\
\hline Cut injury & 7 & 10.8 \\
\hline Total & $\mathbf{6 5}$ & $\mathbf{1 0 0}$ \\
\hline
\end{tabular}

\section{DISCUSSION}

This study showed, suicidal attempt was common in young age group with median age of 29 years. In other studies also, it is common in young individuals $s^{1-3}$. But parasuicide in present study was relatively more among males $(52.3 \%)$ than in females $(47.7 \%)$ in contrast to the previous studies ${ }^{1-3,6,7}$ may be due to small sample size and limited study group (soldiers and their family). But another small Indian study also shows similar finding with $56 \%$ male $^{8}$.

In present study, commonest mode of suicide was OP poisoning $(25,43.1 \%)$, followed by drug overdose/ hanging each 11 (16.9\%) cases. OP poisoning is common 
modality may be due to easy access to OP compounds, Nepal being agriculture based country. While in some studies common mode of the suicide attempt is drug poisoning following violent methods of self-harm ${ }^{2,3,7}$. Suicide is common problem in Korea and it has increased substantially in comparison to other countries where hanging is common modality which follows pesticide use . $^{\text {. }}$

There is interplay of several factors like unemployment, personality character, culture, violence, diseased condition etc in individuals with motives of termination of life in the form of suicide; however there is no study which has proven the direct causal association although studies have shown the significant association of different factors like addiction of the substances ${ }^{10,11}$. One large cohort study among Swedish cohort showed strong association between alcohol consumption with Para suicide and Suicide ${ }^{12}$.

\section{REFERENCES}

1. Welch SS. A review of the literature on the epidemiology of parasuicide in the general population. Psychiatr Serv. 2001 Mar;52(3):368-75. [DOI]

2. Poma SZ, Toniolo E, Grossi A, Pizzo R, Cocchio S, Baldo V. Epidemiology of suicide attempts in a psychiatric setting in Northern Italy. J Psychopathol. 2013;19:119-125. [Full Text]

3. Mauri MC, Cerveri G, Volonteri LS, Fiorentini A, Colasanti A, Manfré S, Borghini R, Pannacciulli E. Parasuicide and drug self-poisoning: analysis of the epidemiological and clinical variables of the patients admitted to the Poisoning Treatment Centre (CAV), Niguarda General Hospital, Milan. Clin Pract Epidemiol Ment Health. 2005 Apr 28;1(1):5. [Full Text]

4. Suokas JT, Perälä J, Suominen K, Saarni S, Lönnqvist J, Suvisaari JM. Epidemiology of suicide attempts among persons with psychotic disorder in the general population. Schizophr Res. 2010 Dec 31;124(1):22-8. [DOI]

5. Marahatta K, Samuel R, Sharma P, Dixit L, Shrestha BR. Suicide burden and prevention in Nepal: the need for a national strategy. WHO South-East Asia journal of public health. 2017 Jan 1;6(1):45. [DOI]
This study prospects the findings about suicidal attempt among soldiers and their family though limiting factor being its sample size and done in restricted populations. In order to prevent suicide, the individual should be provided with education about the impact of the problem and will need problem-solving strategy.

\section{CONCLUSION}

In our locality among the soldiers and their family the common mode of parasuicide is OP-poisoning and is common in young age especially males. But since it is based on small sample size and single center based, large multi-centric or community based study should be done to know further about exact burden of the issue and its proper approach.

\section{LIMITATIONS}

This was the single centered hospital based retrospective study based on soldier and their family so the finding may not be generalizable to all community.

6. Weissman MM, Bland RC, Canino GJ, Greenwald S, Hwu HG, Joyce PR, Karam EG, Lee CK, Lellouch J, Lepine JP, Newman SC. Prevalence of suicide ideation and suicide attempts in nine countries. Psychol Med. 1999 Jan;29(1):9-17. [DOI]

7. Devrimci-Ozguven $\mathrm{H}$, Sayıl I. Suicide Attempts in Turkey: Results of the WHO-EURO Multicentre Study on Suicidal Behaviour. Can J Psychiatry. 2003 Jun;48(5):324-9. [DOI]

8. Arun M, Yoganarasimha K, Palimar V, Kar N, Mohanty MK. Para suicide: An approach to the profile of victims. JIAFM. 2004;26(2):58-61. [Full Text]

9. Noah AJ, Acciai F, Firebaugh G. Understanding the contribution of suicide to life expectancy in South Korea. Demogr Res. 2016 Jul 1;35:617. [DOI]

10. Diekstra RF. Suicide, depression and economic conditions. Current concepts of suicide. 1990:71-94.

11. Govender I. Reasons for parasuicide among patients admitted to Tshilidzini Hospital, Limpopo Province: A qualitative study. S Afr J Psychiatr. 2013 Jan 1;19(4):222-5. [DOI]

12. Rossow I, Romelsjo A, Leifman H. Alcohol abuse and suicidal behaviour in young and middle aged men: differentiating between attempted and completed suicide. J Addict. 1999 Aug 1;94(8):1199-207. [DOI] . 